A R T I G O S

\title{
NOVOS PATRIMÔNIOS, UM NOVO BRASIL? UM BALANÇO DAS POLÍTICAS PATRIMONIAIS FEDERAIS APÓS A DÉCADA DE 1980
}

New heritages, a new Brazil?

An analysis of federal heritage policies after the 1980 s

PAULO CÉSAR GARCEZ MARINS

http://dx.doi.org/10.1590/S0103-21862016000100002

Paulo César Garcez Marins é historiador, doutor em História Social pela USP, docente do Museu Paulista da USP e doS Programas de Pós-Graduação em Arquitetura e Urbanismo e em Museologia da USP (pcgmarins@gmail.com).

Este artigo conclui reflexões apresentadas no IV Seminário de Geografia, Turismo e Patrimônio Cultural realizado na UERJ em outubro de 2012.

Artigo recebido em 1 de fevereiro e aprovado para publicação em 4 de abril de 2016. 


\title{
RESUMO
}

Este artigo examina as práticas de preservação do patrimônio cultural adotadas na esfera federal a partir da redemocratização do país na década de 1980, tendo por foco os bens que alcançaram tombamento e registro. Procura analisar em que medida conceitos de identidade nacional, tradicionalmente acolhidos pelo IPHAN desde a ditadura varguista, foram efetivamente revistos ao se realizarem as seleções de novos bens protegidos.

Palavras-CHAVE: patrimônio cultural; IPHAN; patrimônio edificado; patrimônio imaterial; identidade nacional; tmbamento.

\begin{abstract}
The article examines the practices of conservation of the cultural heritage adopted by the federal government since the democratization of the country in the 1980s, focusing on the heritages nominated by the "tombamento" and "registro". It analyzes to what extent national identity concepts traditionally welcomed by IPHAN since the Vargas dictatorship have been effectively revised when new protected heritages are selected.
\end{abstract}

KEYWORDS: cultural heritage; IPHAN; architectural heritage; imaterial heritage; national identity; preservation.

\section{RÉSUMÉ}

L'article examine les pratiques de préservation de l'héritage culturel adoptées au niveau fédéral depuis la démocratisation du pays aux années 1980, en se concentrant sur les biens culturels classés et enrigistrés. II analyse dans quelle mesure les concepts d'identité nationale traditionnellement accueillis par I'IPHAN depuis la dictature Vargas ont effectivement souffert une révision lors de la sélection de nouveaux biens protégés.

MoTS-CLÉS: héritage culturel; IPHAN; héritage architectural; héritage imateriel; identité nationale; classement. 


\section{INTRODUÇÃO}

um texto curto, mas de capacidade sintética memorável, o sociólogo Sérgio Miceli
lançou uma provocação demolidora na comemoração dos 50 anos do IPHAN (1987: 44-47). Suas palavras apontavam ser esse órgão o executor da política cultural nacional de maior eficácia até então realizada no Brasil, mas questionavam a pertinência da prática do tombamento, e de seus critérios, como instrumento dessa política, tida recorrentemente como uma vitória incontestável das práticas federais de preservação. A continuidade desse instrumento legal, quase implausível em um país de instabilidades institucionais tão frequentes, fora, e ainda era, pautada no jamais revogado Decreto-Lei ํo 25 , norma que sobrevivera às oscilações de um espectro político que acolhia lideranças imensamente distintas, de Vargas a Sarney, e que permanecera a salvo das flutuações partidárias e ideológicas pelos quais passara o Estado nacional. Miceli apontava ainda que, mais do que apenas marcada pela notável continuidade, a ação de preservação do IPHAN fora também pautada por uma evidente coerência conceitual, que definira a rotina da prática do tombamento a partir da aplicação reincidente do ideário modernista, cristalizado e congelado em uma espécie de "refrigério". A canonização da arquitetura monumental, do barroco e da mestiçagem como evidência do ethos nacional chegara à década de 1980 ainda plena de vitalidade, assim como a herança autoritária e excludente das práticas de eleição patrimonial, concentrada nos técnicos e na aparente neutralidade de suas escolhas, derivadas sobretudo da descrição formalista e estilística dos monumentos artísticos.

Passado um quarto de século dessa avaliação contundente e pertinente exarada logo após o fim do regime militar, propõe-se aqui uma análise sobre as possíveis inflexões dessa trajetória de preservação, até então marcantemente conservadora, entre as décadas de 1990 e 2010. Os efeitos práticos de novos marcos legais e de ação política - como a proteção do patrimônio imaterial a partir de 2000 e a significativa ampliação do "estoque patrimonial" de bens materiais tombados ao longo da primeira década do século XXI - serão aqui examinados, de modo a compreender em que medida tais resultados efetivamente alteraram a ideia de Brasil semeada pelos modernistas e pela chamada "fase heroica" após a redemocartização. Os traços de permanência do padrão elitista oriundo tanto das escolhas realizadas quanto dos que escolhem, que Miceli chamou de "marca classista" do IPHAN, da intensa hierarquização 
e da sub-representação dos grupos étnicos e das práticas religiosas, bem como da canonização de uma certa noção de mestiçagem - dimensões essas que serviram simultaneamente à celebração e à opacidade de agentes formadores do Brasil - serão aqui investigados. 0 texto debruça-se tanto sobre as ações voltadas para o patrimônio material quanto àquelas concernentes ao patrimônio imaterial, tidas, em princípio, como inovadoras e capazes de superar o atavismo exclusivo e excludente que é a marca da trajetória federal de preservação no Brasil.

\section{Fim de SÉCUlO: UMA AURORA DE DILATAÇÃO E CONSCIENTIZAÇÃO?}

s duras palavras de Miceli, proferidas em plena década de redemocratização do país,
coincidiram paradoxalmente com um esforço institucional do órgão de preservação federal para ampliar os alvos de processos de tombamento e os grupos sociais por eles referenciados. Os anos 1980 foram de fato marcantes pelo tombamento de bens afeitos a expressões até então ignoradas pelo rol de tombamentos realizados pelo IPHAN, num alargamento perceptivo daquilo que começara a se definir como a "diversidade cultural", frisada na gestão de Aloísio Magalhães no IPHAN entre 1979 e 1982 (Gonçalves, 2002: 120-122).

0 espectro de inovações alcançava desde a escolha de edificações vinculadas a diferentes grupos étnicos que formaram o país (como afro-brasileiros e imigrantes), até aquelas ligadas a vertentes estilísticas da arquitetura que durante décadas haviam sido consideradas pelo órgão como expressões exóticas com relação à tradição tida como efetivamente brasileira, advinda do período colonial, e que se encaixavam na célebre expressão de Lúcio Costa - os meros "hiatos" na linha coerente da verdadeira história da arquitetura nacional. Iniciava-se também a superação do bloqueio ao reconhecimento de outras religiões que não somente a católica como dignas do tombamento de seus templos.

Em 1986, o Conselho do IPHAN aprovou a preservação do primeiro terreiro de tradições religiosas afro-brasileiras - o Terreiro da Casa Branca, Ilê Axé lyá Nassô Oká. Nesse ano também se tombou a Serra da Barriga, sítio onde se situara Palmares, o mais notório dos quilombos do período colonial. Tais proteções ocorreram, emblematicamente, já às vésperas das comemorações do primeiro centenário da Abolição (1988). Se a origem africana começava a ser reconhecida para além da matriz fusionista dos modernistas - que diluíra a formação heterogênea do país pela sobrevalorização das heranças lusitanas e de seus maiores artistas mulatos -, as correntes imigratórias, sobejamente ignoradas nos reinados de Rodrigo Melo Franco e de Lúcio Costa por não serem consideradas como parte da matriz do ethos nacional, passaram a ser inseridas no rol dos bens preservados. São exemplos dessa ampliação os tombamentos do Casarão do Chá de Mogi das Cruzes (SP, 1985 e 1986), da Casa Presser de Novo 
Hamburgo (RS, 1985 e 1986) e do conjunto escolar de Rio dos Cedros (SC, 1985 e 1986), todos protegidos em 1985, além do centro histórico de Antônio Prado, ligado à imigração italiana no Rio Grande do Sul, protegido em 1990. ${ }^{1}$

As vertentes da arquitetura modernista não relacionadas formalmente à "escola carioca", já consagrada por tombamentos precoces desde a década de 1940, passaram a ser reconhecidas, ainda que minimamente, em 1986, mediante a proteção de três casas projetadas por Gregori Warchavchik na cidade de São Paulo. Isso ocorreu ao mesmo tempo em que se ampliava significativamente a proteção de imóveis vinculados ao Ecletismo, sabidamente detestado por Lúcio Costa, por meio do tombamento da Faculdade de Direito do Recife em 1980; do Palácio de Manguinhos no Rio e da sede do Correios em Porto Alegre, ambos em 1981; do Palácio das Laranjeiras e do Colégio Pedro II, no Rio, em 1983; do Paço Municipal de Curitiba em 1984; de palacetes de Belém em Nazaré e na av. Malcher, em 1985; do hotel Copacabana Palace, em 1986; das edificações principais do Porto de Manaus, em 1987; do Prédio da Light carioca, em 1988; ou do Palacete Argentina em Porto Alegre, em 1990. No mesmo sentido, outra novidade foi o reconhecimento de várias edificações, equipamentos urbanos ou elementos estruturais vinculados à "arquitetura do ferro", uma importação industrializada que finalmente passava a ser reconhecida como parte da história material da nação, mediante os tombamentos do portal e armazéns do cais central de Porto Alegre em 1983; da caixa d'água de Pelotas em 1984; do Reservatório do Mocó e do Mercado Municipal de Manaus, em 1985 e 1987; do complexo ferroviário de São João d’El Rey em 1989 ou do chafariz "do Monroe", originalmente localizado no largo do Paço carioca, em 1990.

Tais fraturas no ideal modernista enlaçavam-se à própria indicação de Olinda à condição de patrimônio mundial, nominação alcançada em 1982, na medida em que sua candidatura representava uma revisão da ideia de centro histórico vinculado apenas ao período colonial. As muitas camadas de tempo somadas no conjunto arquitetônico e paisagístico da velha capital pernambucana, visíveis nos casarios e nas igrejas de muitos séculos e estilos compactados nas colinas ao norte do Recife, eram um contraste à ênfase primordial no século XVIII mineiro ou à visão eurocêntrica que priorizava os conjuntos urbanos homogêneos, quase impossíveis no hemisfério meridional.

Diversos tombamentos de centros históricos ocorridos ao longo da década de 1980 protegeram conjuntos heterogêneos como o de Olinda, marcados por diversas temporalidades arquitetônicas. De fato, é a heterogeneidade estilística, com forte presença de estilemas do neoclassicismo e de vocabulários historicistas como o neogótico, que marca os núcleos preservados de Mucugê e Rio de Contas (BA, registrados em 1980 no livro Arqueológico, Etnográfico e Paisagístico, mas não no de Belas Artes) e Laguna (SC, registrados em 1985 nos 
livros Histórico e AEP, mas não no de Belas Artes), o mesmo ocorrendo com o de São Francisco do Sul (SC) em 1987.

A rejeição ou menosprezo aos séculos XIX e XX, ainda que evidente na subclassificação desses sítios aos quais se rejeitou a inscrição no livro das Belas Artes - o mais prestigioso na hierarquia de valores do IPHAN, que optara por priorizar uma leitura estetizante da trajetória brasileira durante a "fase heroica" (Rubino, 1991: 123, Fonseca, 1997: 126-129) -, não impediu que o conjunto da Praça XV carioca, ele também marcado imensamente pelo neoclassicismo e pelo ecletismo, fosse tombado em 1990 e inscrito nos três livros. O Paço, que fora despojado dos acréscimos neocoloniais durante década de 1980 para que fosse restituída sua fisionomia sob o Reino Unido e o Primeiro Reinado, deveria ter seu entorno preservado, ainda que opostos estilisticamente. Essa necessidade de preservar a ambiência urbana de um bem maior do período colonial e imperial, já muito ameaçada por arranha-céus como o Edifício Cândido Mendes, acabou por impor-se a velhos preconceitos que até então impediam que qualquer mancha urbana da cidade, muito heterogênea estilisticamente, fosse tombada pelo IPHAN. Decorridos 17 anos desde o tombamento do Teatro Municipal, da Biblioteca Nacional e do Museu Nacional de Belas Artes em 1973, o ecletismo carioca voltava a ser objeto de proteção, agora num tecido urbano.

As práticas populares são outro ponto a se destacar entre os bens que foram tombados na década de 1980 e que podem sugerir uma inflexão nos critérios de seleção do IPHAN. O presépio mecânico do Pipiripau, localizado em Belo Horizonte e tombado em 1984, a coleção de ex-votos do Santuário de Congonhas (1981) e o conjunto do "sacro monte" de Monte Santo, na Bahia, tombado em 1983, indicam a ampliação antropológica do conceito de patrimônio em curso desde os trabalhos do Centro Nacional de Referência Cultural (CNRC). Tal vivacidade não iria, porém, deitar raízes nos tombamentos das décadas seguintes. Deixou-se primordialmente ao registro do patrimônio imaterial a tarefa de olhar o frágil, o rústico, 0 improvisado e o instável, características opostas às noções de ancianidade, monumentalidade e originalidade que sempre pautaram o IPHAN.

Embora tal agenda de proteção ampliada da década de 1980 seja lembrada por trabalhos que abordam esse período da história do IPHAN como uma espécie de início da superação dos critérios cristalizados da "fase heroica" - sendo compreendida como a evidência de um redirecionamento conceitual e político do órgão que então se ajustava às expectativas democráticas do período e ao alargamento conceitual da noção de patrimônio estabelecida na Constituição de 1988 (Fonseca, 1997: 156) ou que, ao menos, fosse em parte uma ação discursiva ou retórica, mas que pouco afetava o quadro de proteção nacional de maneira efetiva (Mota, 2000: 56-75) -, claro está que tal palpitação foi concorrente à contínua ampliação 
de bens vinculados ao período colonial. Do Forte de Santa Bárbara em Florianópolis (1984) às 13 imagens missioneiras na matriz de São Luiz Gonzaga (RS, 1984); das igrejas de Barbacena (MG, 1988) à matriz de Itatiaia em Ouro Branco (MG, 1983); das ruínas do Engenho do Murucutu, em Belém, às do Sítio do Físico, em São Luís (ambas em 1981); da igreja dos Remédios de Fernando de Noronha (1981) à capela de Santana em Ilhéus (BA, 1984), vários foram os acréscimos que confirmavam mais uma vez a importância central dos legados coloniais, que ainda seria a principal razão para o tombamento dos centros históricos de Santa Cruz Cabrália (BA, 1981), Natividade (TO, 1987), Vila Bela da Santíssima Trindade (MT, 1988) e Pirenópolis $(G 0,1990)$.

Além desse peso da tradição colonial, houve, no âmbito de seu contraponto oposto e complementar, a reconsagração de bens emblemáticos da escola modernista carioca, como a sede da Associação Brasileira de Imprensa, na cidade do Rio de Janeiro, projetada pelos irmãos Roberto (1984), o Hotel do Parque São Clemente, em Nova Friburgo (1985), e o conjunto de três edifícios do Parque Guinle (1986), ambos de Lúcio Costa, e, fechando a década, Brasília, a síntese modernista de Costa e Niemeyer, tombada em 1990, três anos após tornar-se o primeiro bem cultural do século XX considerado patrimônio mundial pela Unesco. Reafirmava-se, assim, e com um imenso êxito internacional como chancela, o teor dos tombamentos - ou "autotombamentos" - do Ministério da Educação e Saúde em 1948, e da Igreja de São Francisco da Pampulha em 1947, que haviam sido realizados pelos modernistas dentro do SPHAN logo após a conclusão desses edifícios. A retomada dos tombamentos dos edifícios da escola carioca na década de 1980 pode ser compreendida como uma ação de autoperpetuação dos herdeiros da geração formadora do SPHAN e, por certo, um sinal de evidente de reação conservadora diante de tantas oscilações conceituais pelas quais passavam os antigos critérios de seleção da memória e da identidade nacionais construídos pelo IPHAN desde a década de 1930.

As inovações acima listadas não chegaram, entretanto, a dar largos frutos ao longo dos 15 anos seguintes. A quebra institucional durante a gestão Collor (que extinguiu o SPHAN/ Pró-Memória e criou o IBPC, igualmente extinto e renomeado como IPHAN no governo Itamar Franco), as levas de aposentadorias desencadeadas pelas reformas previdenciárias da década de 1990, a inexistência de concursos para cargos técnicos, a crescente transferência de interesse do Estado do tombamento para as restaurações subsidiadas pela Lei Rouanet podem ser considerados fatores que ou inviabilizaram ou tornaram pouco atraentes um investimento governamental no prolongamento da discussão dos critérios esboçados na década de 1980.

Se nessa década o IPHAN logrou tombar 85 bens, entre os quais os acima abordados, na década de 1990 esse total não ultrapassaria 36 bens, somando apenas 42,3\% da soma anterior. 
Tombamentos como o da Estação da Luz na capital paulista (1996), da Ponte Herćlio Luz em Florianópolis e do Parque da Independência e Museu Paulista em São Paulo (1998) consistiam prolongamentos importantes da abertura do tombamento federal aos edifícios pré-fabricados ou vinculados ao ecletismo, o mesmo podendo ser dito do tombamento relativo ao conjunto do bairro do Recife (1998), eleito por suas características testemunhais da circulação dos modelos urbanísticos e arquitetônicos franceses em voga na Primeira República. A nominação do terreiro Axé Opô Afonjá em Salvador (2000) foi uma conquista solitária na década de 1990 a seguir 0 pioneiro da Casa Branca, assim como a torá do Museu Nacional, tombada em 1999, era a outra sinalização de que havia bens materiais de outros credos no Brasil que não o catolicismo.

A maioria dos tombamentos de conjuntos urbanos na década de 1990 foi concentrada em áreas geográficas pouco nominadas até então, como o Nordeste semiárido e o Centro Oeste. Corumbá (MS, 1993), Cuiabá (MT, 1993), Laranjeiras (AL, 1996) e Lapa (PR, 1998), todas elas muito marcadas pelos estilos do século XIX e princípios do XX, foram tombadas nos três livros, enquanto a Penedo ( $A L, 1996)$, a Sobral e a Icó (CE, ambos em 1998) foi negado o registro no livro das Belas Artes. Todos eles, entretanto, são muito afins à paisagem urbana luso-brasileira, de lotes profundos de testadas estreitas, com casario basicamente alinhado na testada do lote e sem recuos laterais. Ainda que com marcas neoclássicas ou com sinais mais ousados da Art Nouveau nos sobrados ricos de Corumbá ou em raros palacetes na parte mais alta de Penedo, o que se preservou na eleição desses conjuntos foi a paisagem "típica" luso-brasileira, ainda que atualizada estilisticamente. Nada de bairros operários, bairros-jardins, bairros de palacetes, áreas intensamente verticalizadas ou marcadas pela paisagem industrial.

\section{AMPLIANDO AGENTES, ALARGANDO FRONTEIRAS: PARA ALÉM DO PARADIGMA MODERNISTA?}

S e os tombamentos dos anos 1990 não foram numericamente consideráveis, nem conceitual ou metodologicamente renovadores, tal palidez foi compensada pelo advento da legislação de proteção ao patrimônio imaterial surgida no último ano dessa década. 0 Decreto 3551/2000, que instituiu o registro de bens imateriais, foi uma das bandeiras patrimoniais da era FHC, sendo inclusive antecessor da criação da nominação internacional do patrimônio imaterial pela Unesco, por meio da convenção assinada em 2003 e ratificada pelo Brasil em 2006.

A renovação tipológica (que focalizava, a partir de seus livros de inscrição, saberes, formas de expressão, celebrações e lugares) está conjugada com a grande inovação metodológica na trajetória da preservação federal: a condição de que a proposta de nominação "seja acompanhada de declaração formal de representante da comunidade produtora do bem ou de 
seus membros, expressando o interesse e anuência com a instauração do processo de registro". ${ }^{2}$ Infere-se disso um interesse e compromisso dos agentes sociais de manter o pretendido patrimônio vivo, o que projeta um protagonismo para a sociedade nunca antes pressuposto na legislação patrimonial do Brasil. Some-se a isso o fato de que, na maior parte dos pedidos de registros, os proponentes foram representantes da sociedade (Corá, 2014: 240-241). Esse protagonismo é, entretanto, algo retórico, visto que várias propostas foram estimuladas pelo IPHAN ou pelo Centro Nacional de Folclore e Cultura Popular (Corá, 2014: 234-244), cabendo ainda, no rito processual do registro, um papel fundamental aos técnicos e consultores na formulação e encaminhamento ao Conselho Consultivo dos complexos dossiês justificativos. Tais dossiês, que demandam diversas tipologias de fontes documentais, dados de inventário de reconhecimento e plano de salvaguarda (Corá, 2014: 194-195), são documentos que dependem de procedimentos eminentemente técnicos, algo que atribui aos agentes públicos uma posição central no referendo aos pedidos da sociedade, quando não tenham sido eles próprios os fomentadores dos pedidos. A valorização - e autovalorização - dos anuentes foi, todavia, efetivamente uma novidade.

Esse estímulo normativo à escuta da sociedade contrasta décadas de um papel centralista, quando não esclarecedor, do IPHAN e de seus agentes, que tradicionalmente se postavam no dever de apontar a importância dos legados patrimoniais aos cidadãos ignorantes ou agressores de seus legados culturais. 0 "deslocamento de matriz" a que se refere Ulpiano Bezerra de Meneses (2012: 33) foi um redirecionamento da relação entre o aparelho do Estado e a sociedade que começava a criar fissuras na engenharia do saber patrimonial construído sob a ditadura varguista. Ao poder público caberia, cada vez mais, desde a Constituição de 1988, um "papel declaratório" (Meneses, 2012: 34), o que ainda está longe de estar efetivamente materializado nas listagens de bens já tombados e registrados no país.

A conclamação aos cidadãos para que se manifestassem quanto ao desenho do patrimônio - e quanto ao que acreditavam a respeito de si mesmos como agentes de cultura ganharia outros prolongamentos ao longo da década de 2000. O Programa Cultura Viva (com os Pontos de Cultura, Pontões de Cultura, o Prêmio Cultura Viva, etc.) instituído durante a era Lula, $^{3}$ e a era de Gilberto Gil no comando do MinC, ensejava igualmente que o cidadão fosse o responsável pelo seu acionamento, visto que a ele cabia candidatar-se aos editais abertos para fomento cultural (Turino, 2010), bem como estimulava a formação de redes colaborativas e de inserção digital (Domingues, 2008). A valorização do engajamento do cidadão, no âmbito tanto da produção quanto da preservação cultural, ganhou assim um destaque como fator político das políticas públicas de cultura praticadas pela esfera federal, em que o Estado começava a abdicar de uma longa tradição diretiva que emanava da ditadura varguista. 
Desde 2002, o Conselho Consultivo do IPHAN indicou o registro de 38 bens, sendo 0 último deles a Festa do Pau da Bandeira de Santo Antônio de Barbalha, em 2015. ${ }^{4}$ Há, portanto, uma média de 2,9 nominações anuais, uma média baixíssima que é, em parte, oriunda de uma metodologia mais sofisticada e lenta do que as antigas práticas de identificação e nomeação do patrimônio edificado, tradicionalmente descritivas e feitas sem consulta à sociedade local. Não há, contudo, como negar que o investimento do Estado nessa ação é de escala obviamente irrelevante em relação ao rol de bens materiais, que recebeu 167 tombamentos na década de 2000 e 123 entre 2011 e 2015.

Para além da óbvia questão da escala, cabe problematizar o resultado dessas nominações do patrimônio material e imaterial no que tange à possibilidade de terem efetivamente contribuído para uma revisão do paradigma modernista de entendimento da nação, que regeu, e a meu ver ainda rege, as ações de nominação patrimonial. Comecemos pela estrela reluzente da política federal de cultura, o patrimônio imaterial.

0 exame do rol de bens imateriais registrados desde 2002 evidencia claramente uma manutenção da histórica prevalência do Nordeste e do Sudeste, com 25 dos 38 bens registrados, incluindo-se aqueles bens partilhados por ambas as regiões (os relativos à capoeira) ou com a região Sul (o fandango). Somam, portanto, 2/3 do total. A região Norte conta com 7 registros, o Centro Oeste com 5 e a região Sul com apenas 2, sendo que um deles, o fandango, é dividido com o Sudeste. Tal geografia dos registros imateriais é próxima daquela apresentada pelos bens tombados entre 1938 e 2010, em que o Sudeste detém 45,7\% dos bens protegidos, o Nordeste detém 35,1\% (totalizando ambos 80,8\%), o Sul 11,2\%, o Centro Oeste 5\% e o Norte 3\% (Vieira Filho, 2011: 27). A coincidência não pode ser tomada como eventual, mas deve sim ser compreendida como parte de uma reiterada interpretação do país em que essas duas regiões, base geográfica inicial da colonização portuguesa e locus simbólico da mestiçagem entre brancos e negros, são aquelas que definem o caráter "nacional" desde 0 estabelecimento das políticas culturais na década de 1930. Excluem-se assim, e reincidentemente, as populações indígenas ou imigrantes da centralidade simbólica do país.

A instituição do registro imaterial, que retomava o "saber fazer" que tanto fascinara os técnicos do CNRC nos anos 1970, emergiu como um instrumento capaz de superar a vasta ausência de preservação dos legados culturais vinculados às camadas populares, que não se enquadravam na escala monumental, no erudito e na ancianidade que pautavam o tombamento dos bens materiais. 0 permanentemente evocado Mário de Andrade - e seu fracassado anteprojeto de 1936, já atento à diversidade cultural brasileira - e assim também Aloísio Magalhães - e sua irreverência conceitual diante dos parâmetros consagrados da "fase heroica" que elegeram a materialidade como única evidência de patrimônio brasileiro 
- assumiram então o papel mítico de "fundadores" do registro imaterial (Lima Filho, 2009), muito embora Andrade estivesse muito mais atento à proteção dos bens em si do que de suas formas de transmissão.

A "canonização" de Mário de Andrade - bem como a experiência do Centro Nacional de Referência Cultural, que foi criado em 1975 e seria integrado ao SPHAN anos depois - recolocava em pauta uma certa compreensão de cultura popular lastreada na tradição folclorista como base de entendimento do que seria o universo de referências culturais imateriais a serem protegidas (Amaral, 2015) além de alheia à cultura de massas (Fonseca, 1997: 172). Assim, como também haviam ensinado os fundadores modernistas do SPHAN, assumiu-se mais uma vez a preferência por práticas oriundas dos mesmos povos formadores da síntese racial sacralizada durante a gestão de Rodrigo Melo Franco de Andrade, visão unitarista que os tombamentos inovadores da década de 1980, estabelecidos após a curta gestão de Magalhães, apenas haviam começado a matizar. A memória de Mário de Andrade, sobretudo, era revivificada no que tinha de sensível às práticas do povo, mas também, indiretamente, no que o escritor tinha de avesso, intransigente e intolerante em relação, por exemplo, à imigração, cujos legados não the interessavam por acreditar, como muitos de sua geração, que não eram essencialmente brasileiros.

É fundamental salientar que, com a exceção do frevo e das matrizes do samba carioca, vinculados estreitamente em sua origem à cultura urbana do século XX (no que se pode acrescentar com algum debate também a produção e consumo da cajuína), todos os demais bens imateriais registrados dede 2002 se pautam por estarem enraizados nos tempos coloniais ou do Império. Até o presente momento, no âmbito do marco temporal, há uma evidente opção por associar a identificação da cultura imaterial ao remoto, ao antigo.

Quanto às dimensões de espaço, a primazia dos registros já concluídos recai sobre lugares afastados do processo de urbanização intensa ou de metropolização. Disso é evidência a proeminência radical do registro de práticas de povos indígenas ainda vivendo em situação claramente não urbana (com exceção da Tava gaúcha, na região missioneira), e com pouca assimilação material das sociedades envolventes.

As restrições temporais e espaciais enlaçam-se também àquelas de caráter étnico. $A$ Constituição de 1988, ao evitar a ideia de uma identidade nacional única, abriu as portas do Estado para o reconhecimento da miríade de povos e práticas culturais que compõe o país. 0 registro de bens imateriais iniciado em 2002 certamente caminhou nesse direção, dando evidência e prestígio a práticas culturais indígenas - como aquelas dos Wajapi, Tukano, Arauaque, Maku, Enawenê Nawê, Karajá e Guarani -, assim como a várias outras ligadas a tradições africanas e afro-brasileiras, como o ofício das baianas do acarajé, a capoeira, o jongo, 0 samba de roda, o samba de enredo ou o tambor de crioula. Tal evidência é certamente muito 
mais significativa numericamente nos registros do que nos tombamentos, que ainda estão preponderantemente vinculados à celebração modernista do fusionismo mestiço em que se sobressaem as heranças lusitanas. Os tombamentos jamais priorizaram marcos materiais em que os legados da África ou dos ameríndios fossem os eixos condutores da mestiçagem. Tal perspectiva será retomada à frente.

Mas se os registros realizados, por um lado, são mais abrangentes etnicamente do que os tombamentos, por outro reforçam, como estes últimos, um mapa do Brasil ainda distorcido, com uma evidente hipertrofia do Sudeste e Nordeste e de certas heranças culturais ali praticadas. Nesse sentido, não há como não deixar de notar a evidente permanência do cânone modernista nos conjuntos de bens imateriais registrados, visto que práticas ligadas aos grupos da imigração estão totalmente ausentes da lista dos registros. Embora presentes em todo 0 país, as heranças da imigração são altamente visíveis na região Sudeste e especialmente na região Sul. Nenhum dos dois bens dessa região - que é a minoritária nos registros, embora não o seja demograficamente no país - é ligado às correntes imigratórias que evidentemente a marcam. Descendentes de italianos, ucranianos, poloneses, alemães, japoneses, árabes, espanhóis, povos bálticos, judeus de diversas origens, dispersos por todo o país, mas especialmente concentrados no Sul e no Sudeste, estão ainda sobejamente ignorados na lista dos registros imateriais.

A exclusão da imigração mesmo nas duas regiões meridionais em que suas marcas são incontornáveis alia-se, por outro lado, a uma territorialização dos outros povos "formadores". Práticas de origem indígena ou africana já protegidas vinculam excessivamente esses grupos a regiões específicas, das quais se tornam quase "típicos", ao mesmo tempo em que estão excluídos de outras. Assim, práticas imateriais africanas ainda não foram protegidas no Sul ou no Centro Oeste, como se tais regiões não fossem marcadas por legados afro-brasileiros. Costumes indígenas estão registrados, e associados, apenas ao Norte, Centro-Oeste e Sul, mas estão ausentes nos registros do Sudeste e Nordeste, sendo ali indiretamente lembrados por meio de tradições caiçaras, como o ofício de paneleiras capixaba.

As cinco regiões do país ganham, por meio dos registros já efetuados, uma renovada e conservadoríssima personificação especializada etnicamente, quase como se os tipos regionais consagrados na cultura visual disseminada a partir da Era Vargas (Salgueiro, 2005) fossem perpetuados em pleno século XXI. Ainda que haja inventários concluídos ou em andamento que matizem essas polaridades ou exclusões étnico-regionais, ${ }^{5}$ o rol de bens já registrados é a atualização de uma espacialidade especializada e inventada nos anos 1930 e 1940.

De maneira próxima a tais padrões seletivos e reafirmadores de várias dimensões da identidade nacional propalada pelo IPHAN desde os anos 1930, o formidável crescimento de 
bens tombados desde o primeiro governo Lula assenta-se igualmente num tenso equilíbrio entre tradição e ruptura no que tange às dimensões identitárias de suas escolhas.

Houve um esforço considerável na primeira década do século XXI no sentido de dilatar o que então passou a ser chamado de "estoque patrimonial" do IPHAN no que tange aos bens edificados. Entre 2000 e 2010, a região Sul foi a campeã de nominações, com 34\% dos tombamentos, seguida do Sudeste com $28 \%$, do Centro-Oeste e do Nordeste empatados com 17\%, e da região Norte com 3\% (Porta, 2012: 51). Entre 2011 e 2015, o Sul foi novamente o privilegiado, com $57 \%$ dos tombamentos, seguido mais uma vez pelo Sudeste com $22 \%$, o Nordeste com 15\%, o Centro Oeste com 3\% e a região Norte com $1 \% .{ }^{6}$ Os dados fornecidos anteriormente mostram que tal crescimento não foi capaz de impactar a hegemonia do Sudeste e do Nordeste se computados todos os bens tombados entre 1938 e 2015 (com 45,3\% e $36,4 \%$ dos bens somados, respectivamente 542 e 436 tombamentos), seguidos pelo Sul com $12 \%$ (144), o Centro-Oeste com 3,1\% (38) e Norte com 2,9\% (35). ${ }^{7}$

Ainda que os últimos 13 anos sejam pouco para um contrabalançar efetivo diante de toda a trajetória institucional do IPHAN, não é de forma alguma negligenciável o redirecionamento de prioridade do Departamento do Patrimônio Material (DEPAM) durante as duas gestões Lula, a partir de 2003, com efeitos ainda nas gestões Dilma Rousseff. 0 gráfico abaixo (Figura 1), ${ }^{8}$ publicado no Relatório de Gestão da DEPAM 2006-2010, demonstra claramente a intenção do Departamento de mostrar que houve uma evidente inversão na tendência de queda nas taxas de tombamento por década desde os anos 1960, bem como um franco contraste com os tombamentos nos anos 1990, o menor índice desde a criação do IPHAN:

\section{Figura 1}

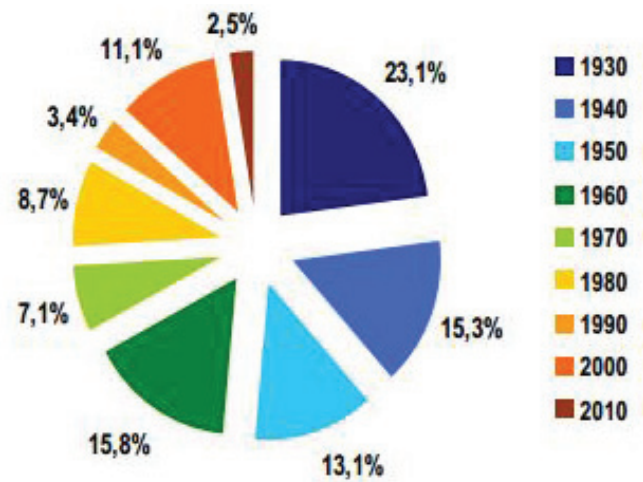

Gráfico de bens tombados por década (1930-1937-39; 1940-1940-49; 1950-1950-59; 1960-1960-69; 1970-1970-79; 1980-1980-89; 1990-1990-99; 2000-2000-09, 2010-2010.) 
Para além da oscilação das quantificações, houve ainda uma ampliação geográfica dos bens registrados para além dos limites das regiões - especialmente visível numa espécie de "ruptura de Tordesilhas", pela qual se materializava um avanço em direção ao Oeste e ao Sul no que tange aos núcleos urbanos tombados. A primazia das cidades litorâneas e daquelas das regiões auríferas mineira e goiana foi contrastada com um aumento significativo de núcleos ou conjuntos tombados ou em estudo nos estados do Piauí, Pará, Paraná, Santa Catarina, Rio Grande do Sul, São Paulo e mesmo num central e eternamente esquecido Espírito Santo (Figura 2): ${ }^{9}$

Figura 2: Cidades Históricas notificadas ou em estudo Localização dos conjuntos tombados e em estudos pelo IPHAN

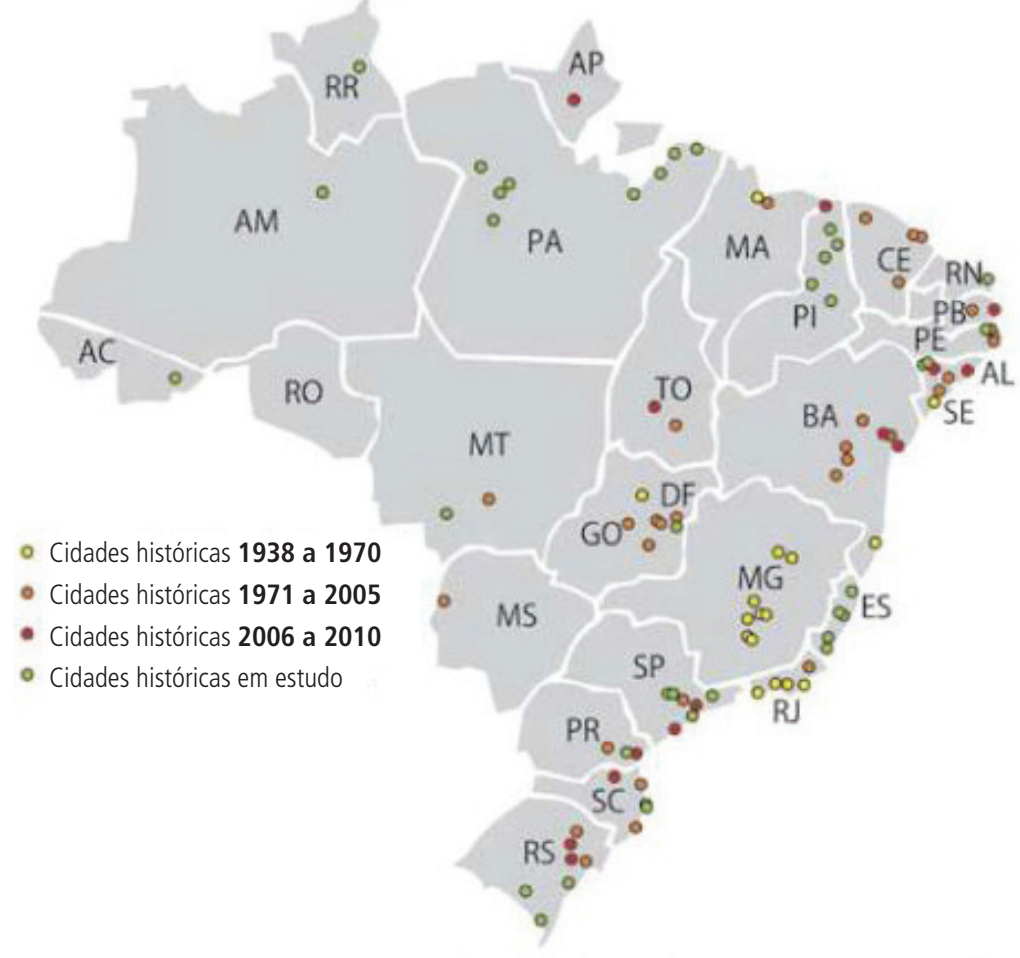

Atualização DEPAM/IPHAM, Dezembro/2010

A inclusão desses centros ou conjuntos urbanos nos livros de tombo é indicativa, contudo, de uma permanência da visão tradicional do IPHAN, de dar prioridade nas inscrições no Livro das Belas Artes aos bens vinculados aos estilos do período colonial e ao modernismo. Indicados a partir de $2003^{10}$ para o Livro Histórico foram Santo Amaro/General Câmara (RS, 2006), Piranhas (AL, 2006), Areia (PB, 2008), Vila de Paranapiacaba (SP, 2008), Porto 
Nacional (TO, 2011), Paranaguá (PR, 2011) e São Paulo/bairro da Luz (SP, 2015); igualmente para o Livro Histórico e para o Livro Arqueológico, Etnográfico e Paisagístico foram designados os núcleos de Marechal Deodoro (AL, 2009), João Pessoa (PB, 2009), Iguape (SP, 2011), Parnaíba (PI, 2011), São Luís do Paraitinga (SP, 2012), Santa Teresa e Jaguarão (RS, 2012), Paracatu (MG, 2012-H, 2015-AEP), São Félix (BA, 2012), Manaus (MA, 2012), Antonina (PR, 2013), Cáceres (MT, 2013), Oeiras e Piracuruca (PI, 2013), e Natal (RN, 2015). A Vila da Serra do Navio (AM, 2012, H, AEP e Belas-Artes), projetada pelo arquiteto modernista paulista Oswaldo Bratke, é o único caso de um conjunto urbano incluído no livro das Belas-Artes, o que, pela filiação plástica de seu projetista, reconfirma o lugar dos modernistas paulistas (como Warchavchik e Lina Bo) no lugar de exceção de uma lógica que negou a conjuntos urbanos marcados pelo neoclassicismo ou pelo ecletismo o status de belo. Vê-se que, também nesse âmbito, os ideais artísticos consolidados na longa gestão de Rodrigo Melo Franco de Andrade e de Lúcio Costa ainda não foram substancialmente postos em xeque.

Essas nominações de bens arquitetônicos, isolados ou em conjunto, basearam-se crescentemente em princípios metodológicos de mobilização da sociedade semelhantes àqueles adotados no registro de bens imateriais. Houve um incremento de práticas de inventário participativo, notáveis sobretudo em projetos relativos ao patrimônio do Vale do Ribeira paulista (Nascimento \& Scifoni, 2015).

Tal esforço de inclusão no âmbito dos tombamentos, visível tanto nas fronteiras geográficas do patrimônio quanto no diálogo com os cidadãos, ainda não é capaz de superar várias pièces de résistance do ideário modernista de desenho do Brasil, fortemente excludente.

Os tombamentos de terreiros, por exemplo, permanecem atávicos a uma exclusiva opção pelo Nordeste, e também primordialmente pelos cultos panteônicos originários da costa ocidental setentrional da África. Após os pioneiros tombamentos do Terreiro da Casa Branca (Ilê Axé lyá Nassô Oká, 1986) e do Axé Opô Afonjá (2000), foram tombados o Bate-Folha Manso Banduquenqué (2005), o Gantois (Ilê lyá Omim Axé Yiamasséo, 2005), o Terreiro do Alaketo (Ilê Maroiá Láji, 2008), o llê Axé Oxumaré (2014), "11 todos localizados em Salvador, e ainda a Casa das Minas Jeje (2005), em São Luís, todos eles vinculados ao candomblé de tradição jeje-nagô, com exceção do Bate-Folha, declarado como candomblé angolano (Giumbelli, 2014: 455-456).

Nenhum terreiro fora do Nordeste foi objeto de tombamento até 2015, configurando uma territorialidade restritiva e associativa, que priva o restante do país do reconhecimento da presença de tradições religiosas afro-brasileiras. Ao mesmo tempo, tal conjunto de tombamentos faz com que o candomblé reine soberano sobre outras práticas religiosas afro-brasileiras. De fato, não há nenhum terreiro de umbanda tombado pelo IPHAN, configurando uma sobrevalorização 
das religiões panteônicas da Costa da Mina e do Golfo do Benin que atualiza a compreensão de que o candomblé é mais puro e "mais africano" do que os demais cultos como a umbanda, tidos como sincréticos. Embora tal dualismo já tenha sido muito problematizado (Dantas, 1982; Ortiz, 1976; Hofbauer, 2011) as escolhas realizadas para tombamento, concentradas sobretudo na Bahia, restauram concepções antigas de primazia e especificidade de seus terreiros e reforçam ser esse estado o sanctum sanctorum da matriz africana da sociedade brasileira.

O candomblé passa, então, a desempenhar um papel de representação da negritude, mas sem que ele possa ser um efetivo caudal de síntese identitária capaz de identificar o Brasil ou possa concorrer, nesse papel, com o catolicismo, tido oficialmente como a religião emblemática do país e capaz de agregar nossas diferenças. Sínteses como a umbanda, em que elementos europeus se justapõem a práticas de origem africana, não são prestigiadas pelo tombamento federal, criando assim uma hierarquia fortemente exclusiva entre os cultos afro-brasileiros, em que o candomblé, obviamente também plástico e sincrético, é isolado e congelado sob a redoma de uma africanidade idealizada.

0 reconhecimento da imigração pelo instituto do tombamento cumpre um papel geográfico oposto ao do candomblé. A presença de imigrantes no Norte, no Nordeste e sobretudo no Sudeste é eclipsada por uma priorização da região Sul, percebida e protegida como o locus privilegiado do imigrante, tido tradicionalmente pelo ideário modernista do IPHAN como estrangeiro.

O centenário da imigração japonesa comemorado em 2008 foi fator de estímulo para que o órgão inovasse ao tombar, em 2010, diversas edificações (fábricas de chá, residências e igrejas cristãs) e uma plantação de chá verde no Vale do Ribeira. Tais escolhas foram resultado de um inventário participativo realizado pelo órgão, para o qual concorreu decisivamente a opinião de moradores locais (Nascimento \& Scifoni, 2015). Mas o estado de São Paulo, maior destino das correntes imigratórias dos séculos XIX e XX no país, permanece isento de ser reconhecido pelos tombamentos (e pelos registros) do IPHAN como portador de tal estatura histórica. Tal eclipse origina-se em parte dos repisados referenciais da "fase heroica" ainda presentes na ação de técnicos do patrimônio material e, por outro lado, na ausência de postulações, nunca proferidas, de praticantes de patrimônios imateriais de origem imigrante no estado, que sequer cogitam que suas práticas possam ter interesse em face do paradigma "nacional" que tradicionalmente os exclui.

Marcos da imigração italiana vêm sendo protegidos na Serra Gaúcha desde 1985 com o tombamento pontual da casa de Dona Neni e depois do núcleo urbano de Antônio Prado (1985 e 1990), e mais recentemente do de Santa Tereza (2012), mas nenhum reconhecimento dessa corrente ocorreu em São Paulo ou em cidades como Belo Horizonte, Salvador, Manaus ou 
Belém, plenas de bens arquitetônicos ligados à imigração vinda da Itália, algo já evidente na bibliografia especializada (Salgueiro, 1997; Puppi, 1998; Derenji, 1998). As imigrações ibérica, árabe ou eslava, concentradas nos estados de São Paulo e Paraná, permanecem absolutamente ignoradas pelos tombamentos federais, assim como as correntes judaicas ashkenazi e sefardi.

Além do tombamento de bens nipo-brasileiros no Vale do Ribeira em 2010, apenas a imigração alemã foi também objeto de uma ação mais contundente do IPHAN no século presente, vinculada ao Projeto Roteiros Nacionais da Imigração. Essa ação levou ao tombamento, em 2007, de diversas edificações rurais e urbanas em 12 municípios catarinenses, ${ }^{12}$ entre as quais também constam algumas vinculadas à imigração italiana. Tais bens foram selecionados a partir de critérios que priorizaram o caráter adaptativo dos colonos, de modo a documentar partidos e soluções construtivas que podem ser compreendidas como expressões recriadas, brasileiras (Vieira Filho \& Weissheimer, 2011).

Ainda que tais tombamentos constituam uma ampliação sem precedentes do rol de bens preservados vinculados à imigração, sua circunscrição ao Sul e extremo-sul do Sudeste reconsagra a imigração numa territorialidade por demais específica no país. Mais do que simplesmente uma restrição espacial, o que se reafirma é a presença pontual das correntes imigrantes, incapazes de afetar o conjunto do país. A reconstrução contínua de suas identidades sinalizadas pela Constituição de 1988, em função de sua presença pontual, é quase guetificada. Não de graça, a ideia de uma "integração" das colônias imigrantes a uma identidade nacional, tida como estável e consolidada desde os séculos coloniais, é ainda presente nos discursos de vários veículos de comunidades vinculadas à imigração (Marins, 2008), excluídas quase que sistematicamente de uma compreensão que os faça parte de interações atravessadas por tensões, trocas e compartilhamentos que os redesenharam e ao país que os acolheu.

\section{CONSIDERAÇÕES FINAIS}

s ações de registro e de tombamento já efetivadas pelo IPHAN nos últimos 35 anos não
representam, obviamente, a totalidade de medidas efetivadas pelo órgão no sentido de rever seus paradigmas, sejam eles identitários, metodológicos ou mesmo políticos. Numerosos estudos técnicos ainda não resultaram em proteções - como parte dos inventários ligados à imigração ou dos INRCs vinculados ao patrimônio imaterial -, o que possibilita que, no futuro, se acentue ou não tendências perceptíveis nos procedimentos de nomeação já concluídos.

É evidente, contudo, que um trabalho crítico de auto-reflexão do órgão federal (explícito, por exemplo, em suas publicações desde a década de 1980), aliado às críticas desferidas nesse período pela imprensa, por agentes políticos ou pelo desdém da população em conservar os 
bens tombados, são fatores que puderam, de alguma forma, colaborar para que o enrijecimento apontado por Sérgio Miceli pudesse ser lentamente desbastado. Seja do ponto de vista de um reconhecimento lento das fraturas e diferenças que constituem o país - e não apenas diversidades ou sínteses apaziguadoras -, seja pela gradual reorientação metodológica que procura trazer os agentes da sociedade civil para o processo de identificação, nomeação e autoproclamação de valores patrimoniais atribuíveis a seus suportes de memória e práticas culturais, as políticas federais de preservação cultural vêm se transformando. 0 peso da tradição, e sobretudo de uma herança conceitual simultaneamente agregadora e segregadora, sintética e hierarquizadora, é parte constitutiva dessa mesma trajetória de patrimonialização, o que certamente não pode ser olvidado para um devir que seja pautado pelo equilíbrio dos agentes que compõe o país.

0 desafio de incluir as referências patrimoniais dos "diferentes grupos formadores da sociedade brasileira" reconhecidos pela Constituição de 1988 permanece. Longe de estarmos numa situação em que o "abuso monumental", a "banalização do patrimônio" ou a "inflação patrimonial" (Debray, 1999; Heinich, 2009) possam ser aqui cogitadas, os 1.195 bens tombados no Brasil e os 38 bens registrados apenas começaram a cumprir a missão de representar a complexidade do país.

\section{NotAS}

1 Os dados sobre os tombamentos realizados pelo IPHAN até 2003 foram retirados da base eletrônica do Arquivo Noronha Santos do IPHAN, disponivel em <http://www.iphan.gov.br/ans/inicial.htm>, último acesso em 15 de maio de 2014; os dados posteriores, até 2012, estão disponíveis em <http://portal.iphan.gov.br/uploads/ckfinder/arquivos/Lista\%20Bens\%20Tombados\%20Dez\%202015.pdf>, último acesso em 15 de janeiro de 2016.

2 Resolução IPHAN no 1, 03/ago/2006, art. 4ํ, inciso VII.

3 Portaria MinC no 156, de 6 de julho de 2004; Portaria MinC ํo 215, de 25 de novembro de 2005.

4 Considera-se para fins de contagem dois registros relativos às práticas sineiras de Minas, dois relativos às práticas da capoeira e dois relativos às bonecas e à cosmologia Karajá.

5 Ver indicações disponíveis em http://portal.iphan.gov.br/pagina/detalhes/681/ (inventários realizados, em que constam, por exemplo, lugares de culto de matrizes africanas e afro-brasileiras no Distrito Federal ou a celebração nipo-brasileira Tooro Nagashi, em São Paulo) e em http://portal.iphan.gov.br/pagina/detalhes/680/ (inventários em andamento, em que constam os estudos do queijo kochkase de origem alemã e de clubes de caça e tiro em Santa Catarina).

6 Dados extraídos de Bens tombados e processos de tombamento em andamento (Atualização: 09.12.2015), disponível em: http://portal.iphan.gov.br/uploads/ckfinder/arquivos/Lista\%20Bens\%20Tombados\%20por\%20 Estado.pdf.

7 Idem.

8 Gráfico extraído de Vieira Filho, 2011: 26. 
9 Mapa extraído de Vieira Filho, 2011: 27.

10 Os anos referem-se à última posição dos processos, podendo estar inscritos nos livros de tombo, homologados (Porto Nacional, São Paulo e Natal) ou sob pendência (Manaus), mas já todos com votação positiva do Conselho Consultivo.

11 Estão já aprovados pelo Conselho, mas ainda sem registro dos livros, o Omo llê Agbôulá, em Itaparica (2015, aprovação), e o Zogbodo Male Bogun Seja Unde (Roça do Ventura), em Cachoeira (2015, homologado pelo ministro).

12 Localizados em Ascurra, Blumenau, Indaial, Itaiópolis, Jaraguá do Sul, Joinville, Orleans, Pomerode, Timbó, Urussanga, Vargem e Vidal Ramos.

\section{REFERÊNCIAS BIBLIOGRÁFICAS}

AMARAL, Leandro Ribeiro do. Historicidade e aspectos centrais da política federal do patrimônio cultural imaterial: uma interpretação. Revista CPC, São Paulo, n.19, p.8-32, jun. 2015.

ANGOTTI-SALGUEIRO, Heliana. A construção de representações nacionais: os desenhos de Percy Lau na Revista Brasileira de Geografia e outras "visões iconográficas" do Brasil moderno. Anais do Museu Paulista: História e Cultura Material, São Paulo, v.13, n.2, p. 21-72, jul.-dez. 2005.

CORÁ, Maria Amelia Jundurian. Do material ao imaterial: patrimônios culturais do Brasil. São Paulo: EDUC; FAPESP, 2014.

DANTAS, Beatriz Góis. Repensando a pureza nagô. Religião e sociedade, Rio de Janeiro, n. 8, p. 15-20, 1982. DEBRAY, Régis (org.). L'abus monumental?. Paris: Éditions du Patrimoine; Fayard, 1999.

DERENJI, Jussara Silveira. A arquitetura nortista: a presença italiana no início do século XX. Manaus: Secretaria de Cultura/Governo do Estado do Amazonas, 1998.

DIOGO, Érica (org.). Recuperação de imóveis privados em centros históricos. Brasília: IPHAN / Programa Monumenta, 2009.

DOMINGUES, João Luiz Pereira. Programa Cultura Viva: políticas culturais para a emancipação das classes populares. Dissertação (Mestrado) - Universidade do Estado do Rio de Janeiro, Rio de Janeiro, 2008.

FONSECA, Maria Cecília Londres. O patrimônio em processo - trajetória da política federal de preservação no Brasil. Rio de Janeiro: Ed. UFRJ; Brasília: IPHAN, 1997.

GASTAL, Susana. Projeto Monumenta: filosofia e práticas em interface com o turismo. Turismo em análise, São Paulo, v. 14, n.2, p. 77-89, nov. 2003.

GIUMBELLI, Emerson. Recomposing the Nation. Conceptions and effects of heritage preservation in religious universes. Vibrant - Virtual Brazilian Anthropoly. vol.11 n.2 Brasília July/Dec. 2014. Disponível em: http:/l www.scielo.br/pdf/vb/v11n2/a15v11n2.pdf. Acesso em 31/mar/2016.

GONÇALVES, José Reginaldo Santos. A retórica da perda - os discursos do patrimônio cultural no Brasil. 2ā ed. Rio de Janeiro: Ed. UFRJ; IPHAN, 2002.

HEINICH, Nathalie. La fabrique du patrimoine - « de la cathédrale à la petit cuillère ». Paris: Ed. de la Maison des Sciences de l'Homme, 2009. 
HOFBAUER, Andreas. Pureza nagô, (re)africanização e dessincretização. In: XI Congresso Luso Afro Brasileiro de Ciências Sociais - Diversidades e (Des)igualdades 2011, Salvador, BA. Anais. Disponível em: http://www. xiconlab.eventos.dype.com.br/resources/anais/3/1307740063_ARQUIVO_2011_Luso-Afro-Bras_2_Purezanago-reafricanizacao-dessincretizacao.pdf. Acesso em: 31/mar/2016.

HUYSSEN, Andreas. Seduzidos pela memória, 2ª ed. Rio de Janeiro: Aeroplano, 2004.

LIMA FILHO, Manuel Ferreira. Da matéria ao sujeito: inquietação patrimonial brasileira. Revista de Antropologia, São Paulo, v. 52, n. 2, p. 605-632, 2009

MARINS, Paulo César Garcez. Cem anos de imigração japonesa no Brasil: horizontes de convívio. In: Ol, Célia; MARINS, Paulo César Garcez (org.). O Japão em cada um de nós (catálogo de exposição). São Paulo: Banco Real, 2008, p. 11-21.

Do Luz Cultural ao Monumenta: sobre a opção pela escala monumental na preservação de uma área de São Paulo. In: BAPTISTA, Dulce Tourinho; GAGLIARDI, Clarissa M. R. (org.). Intervenções urbanas em centros históricos - Brasil e Itália em discussão. São Paulo: EDUC / PUCSP; CNPq, 2012, p. 145-169.

MENESES, Ulpiano Toledo Bezerra de. 0 campo do patrimônio cultural: uma revisão de premissas. In: SUTTI, Weber (coord.). I Fórum Nacional do Patrimônio Cultural: sistema nacional de patrimônio cultural - desafios, estratégias e experiências para uma nova gestão. Brasília: IPHAN, 2012, p. 25-39.

MICELI, Sérgio. SPHAN: refrigério da cultura oficial. Revista do Patrimônio Histórico e Artístico Nacional, Brasília, n. 22, p.44-47, 1987.

MOTTA, Lia. Patrimônio urbano e memória social - práticas discursivas e seletivas de preservação cultural, 1975 a 1990. Dissertação (Mestrado em Memória Social e Documento) - UNIRIO, Rio de Janeiro, 2000.

NASCIMENTO, Flavia Brito do; SCIFONI, Simone. Preservación del patrimonio cultural y participación social: las experiencias en Iguape y Registro (San Pablo, Brasil). Revista America Patrimonio, Santiago, n. 7, p. 127-137, jul.-dez. 2015.

ORTIZ, Renato. A morte branca do feiticeiro negro. Cadernos CERU, São Paulo, v. 9, p. 119-125, 1976.

PORTA, Paula. Política de preservação do patrimônio cultural no Brasil. Brasília: IPHAN, 2012, p. 51

PUPPI, Suely de Oliveira Figueiredo. A arquitetura dos italianos em Salvador, 1912-1924. Monumentos de traços europeus e modernização urbana no início do século XX. Dissertação (Mestrado em Arquitetura e Urbanismo) - FAUUSP, São Paulo, 1998.

RUBINO, Silvana. As fachadas da história: os antecedentes, a criação e os trabalhos do Serviço do Patrimônio Histórico e Artístico Nacional, 1937-1968. Dissertação (Mestrado em Antropologia) - IFCH/Unicamp, Campinas, 1991.

SALGUEIRO, Heliana Angotti. La casaque d'Arlequin: Belo Horizonte, une capitale écletique au XIXe siècle. Paris: EHESC, 1997.

SANT'ANNA, Márcia. A cidade-atração: a norma de preservação de centros históricos no Brasil dos anos 90. Tese (Doutorado em Arquitetura e Urbanismo) - UFBA, Salvador, 2004.

TURINO, Célio. Pontos de cultura: 0 Brasil de baixo para cima, 2a ed. São Paulo: Anita Garibaldi, 2010.

VIEIRA FILHO, Dalmo. Relatório DEPAM 2006-2011. Brasília: IPHAN, 2011. Mimeo.

—_WEISSHEIMER, Maria Regina. Roteiros nacionais de imigração: Santa Catarina. Brasília: IPHAN, 2011. 2 vol.

WIPFLI, Mônica. Intervenções urbanas em centros históricos - estudo de caso da Cidade de Salvador. Dissertação (Mestrado em Arquitetura e Urbanismo), USP, São Paulo, 2001. 